\title{
Cross-domain scenario data model for the matching of comparable disaster situations
}

Monika Friedemann ${ }^{1}$, Fabian Henkel ${ }^{1}$, Benjamin Barth ${ }^{2}$, Jordi Vendrell ${ }^{3}$, David Martin ${ }^{3}$, Michael Nolde $^{1}$, Torsten Riedlinger ${ }^{1}$

Our ecosystems are facing increasingly extensive and complex natural disasters originating from natural or man-made hazards. Examples include the wild fires in Portugal 2017, Chile 2017, California 2018 and most recently Australia 2019/2020 as well as widespread flood events in Austria and the Czech Republic in 2013 and in Serbia and Croatia in 2014. These complex crisis situations highlight the increasing demands of stakeholders to monitor, anticipate, prepare for and learn from disasters. Research and innovation in this area needs to revolve around the expertise and guidance from practitioners in order to find solutions that are accepted and to benefit from their domain knowledge. In the European Commission (EC) H2020-funded project HEIMDALL on a Multi-Hazard Cooperative Management Tool for Data Exchange, Response Planning and Scenario Building we address the challenge of co-designing technological solutions for an improved adaptive emergency management at local, regional, national and European level with a multi-disciplinary group of experts including firefighters, police, emergency medical services, command and control and civil protection.

In order to find the most practical scenario-based solutions we follow a three-step approach: 1) Identification of immediate and long-term prevention and response planning activities that involve complex multi-hazard scenarios and information that needs to be represented in a conceptual scenario model to improve these activities; 2) Extension of that scenario data model by a harmonized lessons learnt data structure which allows stakeholders to capture experience of the emergency management in complex disasters; 3) Development and implementation of a scenario matching tool which allows users to find situations with a similar context, environmental conditions, hazard behaviour and stressed capabilities, from local storage as well as shared by other organizations. We believe that the combination of recording and matching scenarios including lessons learnt from prior incidents can improve the ability of stakeholders to learn and evolve from complex situations and thereby allow them to respond more effectively and operate more efficiently during disasters. Results of successive user exercises and evaluations of the implemented products and tools throughout the project underpin this assumption and at the same time indicate future research needs.

The HEIMDALL project has received funding from the European Union's Horizon 2020 research and innovation program under grant agreement No 740689.

\footnotetext{
${ }^{1}$ German Aerospace Center, German Remote Sensing Data Center, Münchener Straße 20, 82234 Weßling, Germany, monika.friedemann@dlr.de, fabian.henkel@dlr.de,michael.nolde@dlr.de, torsten.riedlinger@dlr.de

${ }^{2}$ German Aerospace Center, Institute of Communications and Navigation, Münchener Straße 20, 82234 Weßling, Germany, benjamin.barth@dlr.de

${ }^{3}$ Fundació d'Ecologia del Foc i Gestió d'Incendis Pau Costa Alcubierre (Pau Costa Foundation), Av. Mossèn Cinto Verdaguer, 42 baixos $2 \mathrm{~A}$, 08552 Taradell, Spain, jvendrell@paucostafoundation.org, dmartin@paucostafoundation.org
} 